\title{
ANÁLISE DA RENTABILIDADE DA PRODUÇÃO DE MILHO, SOJA, SORGO E CANA-DE-AÇUCAR NO MUNICÍPIO DE RIO VERDE-GO
}

\author{
Rúbia Cristina Arantes Marquesa ${ }^{\mathbf{a}}$, Alcido Elenor Wander ${ }^{\mathbf{b}}$, Bento Alves da Costa Filho ${ }^{\mathbf{c}}$ \\ ${ }^{\mathbf{a}}$ IF Goiano, Campus Rio Verde - GO; ${ }^{\mathbf{b}, \mathbf{c}}$ Faculdades Alves Faria (ALFA), Goiânia-GO
}

\section{Resumo}

Este trabalho teve como propósito analisar comparativamente a rentabilidade das culturas de soja, milho e sorgo com a cana-de-açúcar no município de Rio Verde-GO na safra 2009/2010. A metodologia utilizada para apurar a rentabilidade das culturas foi a metodologia de cálculo de custo de produção da Companhia Nacional de Abastecimento (CONAB), a partir da qual construiu-se planilhas de custos com os dados dos quatro produtores pesquisados das culturas por eles cultivadas na safra 2009/2010. Como a cana é uma cultura com o ciclo de cinco anos, foram empregados dados da série histórica de custo dos grãos da CONAB e da série histórica da ORPLANA para os custos da cana. O preço dos grãos foi fornecido pela Federação da Agricultura e Pecuária do Estado de Goiás (FAEG) e da cana pela CONSECANA. Analisando a série histórica de custos de produção, renda bruta e resíduo econômico das commodities analisadas, observou-se que nas safras 2005/2006 e 2006/2007 a soja e o milho safrinha apresentaram resultado negativo e a cana apenas na safra 2007/2008; analisando a safra 2009/2010 das quatro propriedades estudadas a cana-de-açúcar apresentou em todas elas um resultado positivo de $100 \%$ a mais do que a soja e o milhou e/ou sorgo juntos.

Palavras-chave: Custo de Produção, Rentabilidade, Cana-de-açúcar.

\begin{abstract}
This study aimed to comparatively analyze the profitability of soybean, corn and sorghum with sugar cane in Rio Verde-GO in 2009/2010. The methodology used to determine the profitability of crops was the methodology of calculation of production cost of the National Supply Company (CONAB), from which it was constructed cost spreadsheets with data from four producers surveyed crops grown by them in 2009/2010 season. As sugarcane is a crop with the cycle of five years, were employed in the time series data of the cost of grain and CONAB series of ORPLANA costs for sugarcane. The price of grain was provided by the Federation of Agriculture and Livestock of the State of Goiás (FAEG) and sugarcane by CONSECANA. Analyzing the historical cost of production, gross income and net profit for considered commodities, it was observed that the crop 2005/2006 and 2006/2007 soybean and maize of $2^{\text {nd }}$ harvest and sugarcane were negative only in 2007/2008 harvest. Analyzing the 2009/2010 crop of four farms studied, cane sugar had positive result in all of them, generating a net profit of more $100 \%$ higher than soybean and corn and/or sorghum together.
\end{abstract}

Keywords: Production costs, profitability, sugar cane.

Recebido 04/11/2012; Aceito 22/12/2012

RBPD - Revista Brasileira de Planejamento e Desenvolvimento, v. 1 , n. 1 , p. 61-75 , jul./dez. 2012 


\section{Introdução}

A agricultura no Brasil tem grande influência dentro da economia. Hoje, cada vez mais, os produtores rurais questionam sobre: $O$ que plantar? Quais atividades são mais lucrativas? Quais são as tendências de mercado? Quais culturas são mais adequadas para empresa rural? Essas questões têm suas respostas encontradas através de conhecimentos adquiridos pelos empresários rurais, gerados pela tecnologia da administração.

A competitividade atual da economia tem demonstrado ser determinante do sucesso ou decadência, para empresas rurais, a capacidade organizacional, o planejamento, o controle para operar com baixos custos. Esses são alguns dos fatores fundamentais para a sobrevivência e continuidade no meio agrícola.

No município de Rio Verde-GO, existe ainda a questão da substituição da soja por cana-de-açúcar, o que gera muito receio na sociedade, pois se teme que a estrutura produtiva e econômica, que é baseada no cultivo e processamento de grãos e de outros produtos cujos grãos são fontes de alimentação para suínos e aves, sofra um abalo e diminuição da oferta de emprego.

A Lei Municipal 5.200/2006 foi instituída com o intuito de barrar o avanço da canade-açúcar nesse município. Essa Lei foi criada, aprovada e implementada no município de Rio Verde com o intuito de frear a expansão da cana-de-açúcar no município. No entanto, a implantação dessa política pública, na forma da Lei municipal, não conteve o avanço do cultivo de cana-de-açúcar no município. Ela apenas fez com que as indústrias que poderiam vir a se fixar no município se instalassem em municípios vizinhos, que ficam com a arrecadação dos impostos enquanto Rio Verde fica com o passivo social (RIO VERDE, 2010).

Sendo assim, já que a chegada da cana-de-açúcar em Rio Verde é uma realidade, há a necessidade de analisar, comparativamente, a rentabilidade das culturas a fim de fornecer subsídios para tomada de decisão por parte dos produtores que, diante desse novo cenário, têm a possibilidade de diversificar suas atividades.

Por serem commodities, a soja, o milho, o sorgo e a cana-de-açúcar têm seus preços de venda estabelecidos pelo mercado mundial, sendo que o controle dos seus custos é fundamental para concorrer diretamente nesse mercado globalizado dos produtos agrícolas. Em virtude disso, os empresários rurais necessitam de um controle de custos eficiente e de informações precisas quanto à rentabilidade líquida de cada atividade para o eficiente gerenciamento de suas empresas rurais.

Isto posto, o presente trabalho justifica-se pelo fato de que a maioria dos produtores rurais desconhece as técnicas administrativas e de controle, imaginando, muitas vezes, que apenas por ter disponibilidade da terra, do capital e de novas possibilidades de cultivo serão coroados pelo sucesso; outros imaginam que sem a disponibilidade do capital, mas com a propriedade da terra e linhas de crédito disponíveis, conseguirão obter resultados positivos, e assim, sucessivamente, surgem 'achismos' de sucesso.

Assim, este trabalho teve por objetivo analisar comparativamente a rentabilidade das culturas de soja, milho, sorgo, cana-de-açúcar no município de Rio Verde-GO. 


\section{Empresa rural}

A administração rural é o conjunto de atividades que facilita aos produtores rurais tomar decisões, visando obter o melhor resultado econômico do negócio e mantendo a produtividade da terra.

Portanto, faz-se necessário conhecer o conceito de empresa rural que, para Noronha (1981, p.9) significa que "empresa rural é o complexo família-fazenda, cujos recursos são dedicados à produção agropecuária, sem necessariamente assumir personalidade jurídica".

De acordo com Crepaldi (1998, p.23), "é a unidade de produção em que são exercidas atividades que dizem respeito a culturas agrícolas, criação de gado ou culturas florestais, com a finalidade de obtenção de renda".

O autor ainda pontua que a empresa rural é integrada por um conjunto de fatores de produção que são: a terra, o capital, e o trabalho. Desses fatores, o mais importante é a terra, pois nela se aplicam os capitais e se trabalha para obter a produção. Assim, uma das preocupações fundamentais que o empresário rural deve ter é conservar a capacidade produtiva da terra.

Hoje, a administração rural é eficiente e, segundo Crepaldi (1998), deve ser estruturada com escritórios de base na cidade e na fazenda, os departamentos devem ser estruturados de modo que cada departamento tenha uma pessoa qualificada e capaz de assumir a responsabilidade integral pelos resultados do empreendimento. $\mathrm{O}$ administrador deve planejar, organizar, dirigir e controlar todo o fluxo de informações e serviços da empresa.

Com a agricultura cada dia mais voltada para o mercado, o crescimento e a sobrevivência da empresa rural depende, em grande parte, da capacidade empresarial de seus gestores que devem tomar decisões com base em conhecimentos técnico-administrativos e ter informações atualizadas sobre condições de produção, comercialização de insumos e produtos (NORONHA, 1981, p.11).

O sucesso de qualquer empreendimento está subordinado a uma administração rural eficiente e a um grau de gerenciamento com habilidade técnica e administrativa para o aproveitamento racional dos recursos à sua disposição.

A contabilidade de custos se constitui num importante e eficiente instrumento para auxiliar na administração das empresas rurais. As informações captadas relativas aos custos das propriedades rurais são utilizadas como referências para o controle dos custos de produção já que os preços são determinados pelo mercado.

\section{Principais terminologias em custos}

A contabilidade de custos utiliza terminologias (conjunto de termos rigorosamente definidos) próprias de custos, permitindo uma uniformização de conceitos.

Na visão de Martins (2003) desde que duas pessoas resolvam comunicar-se, é absolutamente necessário que passem a dar aos objetos, a conceitos e a ideias o mesmo nome, sob pena de no mínimo reduzir-se o nível de entendimento.

Infelizmente, encontra-se em todas as áreas, principalmente nas sociais e econômicas, em particular, uma profusão de nomes para um único conceito e também conceitos diferentes para uma única palavra. 


\subsection{Gastos}

Santos, Marion e Segatti (2002, p.35) dizem que "é todo sacrifício para aquisição de um bem ou serviço com pagamento no ato (desembolso) ou no futuro (cria uma dívida)".

\subsection{Desembolso}

"Pagamento resultante da aquisição de um bem ou serviço. Pode ocorrer concomitantemente ao gasto (pagamento à vista) ou depois deste (pagamento a prazo)" (CREPALDI, 1998, p.89). Ex.: aquisição de imóveis rurais, aquisição de insumos etc.

\subsection{Investimento}

Berti (2002) enfatiza que investimento é o gasto para aquisição de ativo, com a finalidade de obtenção de benefícios a curto, médio e longo prazo. (Todo custo é um investimento, mais nem todo investimento é um custo). Ex.: Matéria prima, máquinas e equipamentos para a fábrica, ações de outras empresas etc.

\subsection{Custo}

Martins (2003, p.24) relata que custo é "gasto relativo a bem ou serviço utilizado na produção de outros bens ou serviços".

Para Berti (2002) custo é um gasto relativo a um bem ou serviço utilizado na produção de outros bens ou de outros serviços. Também é um gasto, só que é reconhecido como custo no momento da fabricação de um produto ou na realização de um serviço.

Noronha et al. (2001, p.31) conceituam que "Custos são desembolsos, efetivos ou imputados, que tornaram possível a geração de determinada quantidade de produto ou serviço". Assim, todos os gastos quando são requisitados no processo produtivo passam a ser chamados de custos. Ex.: Fertilizantes, Sementes, Defensivos, Embalagens etc.

\subsection{Despesa}

Santos, Marion e Segatti (2002, p.36) asseguram que "é todo consumo de bens e serviços para a obtenção de receita".

\subsection{Perda}

Martins (2003, p.24) revela que a perda é "bem ou serviço consumido de forma anormal ou involuntária”.

\subsection{Receitas}

Santos, Marion e Segatti (2002, p.35) afirmam que "a Receita corresponde, em geral, a venda de mercadorias ou prestações de serviços".

\subsection{Ganhos}

Santos, Marion e Segatti (2002) deduzem que da mesma forma que perda, o ganho é bastante aleatório. É um lucro que independe da atividade operacional da empresa. Ex.: ocorre quando se vende uma máquina agrícola por um valor acima de seu custo. 


\section{Classificação de custos}

Na contabilidade de custos, há outra classificação que é a dos custos diretos e custos indiretos. De acordo com Leone (1996), a diferença dos custos da empresa serem classificados como custos diretos e indiretos é basicamente a necessidade de cálculo o mais realístico possível para sua alocação ao produto ou serviço.

\subsection{Custos diretos}

Medeiros (1994) salienta que os custos diretos são os custos que podem ser diretamente apropriados aos produtos, bastando haver uma medida de consumo (quilograma de materiais consumidos, embalagens utilizadas, horas de mão-de-obra empregadas e até quantidade de força consumida).

São os identificados com precisão no produto acabado através de um sistema e um método de medição, e cujo valor é relevante, como: horas de mão-de-obra; quilos de sementes ou rações; gastos com funcionamento e manutenção de tratores (SANTOS; MARION; SEGATTI, 2002 p.43).

\subsection{Custos indiretos}

Os custos indiretos, para serem incorporados aos produtos, necessitam de um sistema de rateio (processo de divisão dos custos indiretos de produção aos produtos, observando critérios pré-estabelecidos para sua alocação). Ex.: Depreciação de equipamentos agrícolas: são utilizados na produção de mais de um produto agrícola.

\subsubsection{Rateio dos custos indiretos}

O rateio representa a alocação dos custos indiretos aos produtos em fabricação, segundo critérios racionais. Dada à dificuldade de fixação de critérios de rateio, tais alocações carregam consigo certo grau de arbitrariedade.

\subsection{Custos fixos e custos variáveis}

Martins (2003) apresenta outra classificação que é a que leva em consideração a relação entre o valor total de um custo e o volume de atividade numa unidade de tempo. Divide os Custos em Fixos e Variáveis.

Noronha et al. (2001) afirma que custos fixos e variáveis podem ser classificados como caixa e não caixa, sendo que caixa são aqueles em que há a efetiva saída de dinheiro para sua aquisição e que não variam em determinado limite de produção. E custos não caixa são definidos como aqueles em que não há a efetiva saída de dinheiro para sua aquisição, no entanto, oneram a atividade em que estão ligados Ex.: Mão-de-obra permanente, arrendamentos, seguros etc.

\subsubsection{Custos fixos}

Santos, Marion e Segatti (2002, p. 43) ponderam conceitualmente que "custos fixos são os que permanecem inalterados em termos físicos e de valor, independentemente do volume de produção e dentro de um intervalo de tempo relevante". 


\subsubsection{Custos Variáveis}

Custos variáveis: Martins (2003) conceitua que custos variáveis são os materiais diretos consumidos cujos custos variam de acordo com o volume de produção; logo, materiais diretos são custos variáveis.

\section{Formação de custos de produção}

Existem várias metodologias para formação de custos, em se tratando de custos agropecuários destacam-se principalmente: a metodologia do Custo de Produção usada pela CONAB (Companhia Nacional de Abastecimento) que foi em maio de 2010 reestruturada; a metodologia de custo total da atividade (CTA) usada por Noronha et al. (2001) e a metodologia do Custo Operacional desenvolvida pelo IEA (Instituto de Economia Agrícola).

A CONAB criou uma metodologia "que busca contemplar todos os itens de dispêndios, explícitos ou não, que devem ser assumidos pelo produtor, desde as fases iniciais de correção até a fase inicial de comercialização do produto". Sua metodologia considera despesas e as subclassifica em despesas de custeio, despesas pós-colheita e despesas financeiras, os custos em fixos e variáveis e, por fim, a renda de fatores como a terra é uma metodologia bastante consultada em se tratando de séries históricas, pois a CONAB disponibiliza uma série histórica de dados, o que viabiliza o seu uso em estudos de custo na série histórica, e que por esse motivo foi empregada neste trabalho.

Noronha et al. (2001, p. 29) reconhecem que "o custo de produção é composto por todos os desembolsos em dinheiro, em espécie ou imputados que ocorrem para que a fazenda ou empresa transforme insumos em produto, durante um período definido de tempo." Esse autor considera todos os itens a seguir distinguindo e separando cada um em caixa e nãocaixa: receitas operacionais e não operacionais, custos variáveis e fixos, despesas operacionais e não operacionais, depois dessas classificações, finalmente se chega ao resultado da atividade analisada.

Custo operacional ou custo de produção é "a soma dos valores de todos os serviços produtivos dos fatores aplicados na produção de uma utilidade" (MATSUNAGA et al., 1976, p.124).

A metodologia do custo operacional tem a proposta de ser a mais simples e objetiva possível, o custo operacional então é composto por todos os custos anteriormente considerados variáveis que representam as saídas financeiras de dinheiro da empresa e somados a estes os considerados fixos, mesmo que não tenham saída de dinheiro, considerase ainda os demais gastos com impostos e taxas ligados à produção (MATSUNAGA et al., 1976, p.132).

Essa metodologia ainda segundo os mesmos autores, permite analisar e tomar decisões a curto prazo. O valor final de renda líquida deve remunerar os demais fatores até então não considerados como terra, capital e mão-de-obra do produtor (MATSUNAGA et al., 1976).

\section{Rentabilidade e maximização econômica}

Dentro das condições de livre concorrência, o objetivo de qualquer empreendedor é o de distanciar o espaço existente entre o custo de produção e o preço de venda que é o lucro. Observado sob a ótica dos fatores de produção, isto significa que a capacidade empresarial, representada pela decisão do produtor, é a chave do processo. Assume-se que, nesse ponto, o conceito de produtor agrícola se equivale ao de empreendedor agrícola. Paralelamente, propriedade agrícola é equivalente a empresa. Tendo como objetivo o lucro máximo, o produtor não pode prescindir de conhecer seus custos fixos, variáveis e totais. Esta é uma 
parte da equação. A outra, que se faz necessário, é desenvolver mecanismos para obter o melhor preço de venda de acordo com as condições vigentes no mercado num determinado momento.

Lacki (2011) relata que "a rentabilidade na agricultura brasileira pode e deve ser semeada e colhida pelos próprios produtores rurais, inclusive pelos pequenos e pobres. Estes também podem ser eficientes [...] e quando o forem, simplesmente deixarão de serem pobres".

$\mathrm{O}$ aumento da rentabilidade do setor exige uma ruptura do atual sistema de dependência existente entre o produtor e as cooperativas e indústrias na fase de preparação dos produtos agrícolas para o mercado. Os preços, em escala internacional, são formados de forma livre, pela ação das forças de oferta e demanda.

\section{Metodologia}

O escopo desta pesquisa envolve informações sobre custos, bem como sua utilização como provedora de informações para controles gerenciais em propriedades rurais (empresas rurais) que cultivem soja, milho, sorgo e cana-de-açúcar e que estavam no município de Rio Verde-GO.

\subsection{Delimitação}

O município de Rio Verde-GO foi escolhido por ser o maior produtor de grãos do Estado, e por estar se tornando também produtor de cana-de-açúcar, tem sua área ocupada em $70,49 \%$ com estabelecimentos rurais com áreas acima de 500 hectares (grandes produtores), com estabelecimentos rurais que utilizam tecnologia e estão sempre dispostos a novos projetos e novos cultivares. A cidade conta com uma cooperativa agroindustrial de grande porte, com cooperativas de crédito, várias associações e sindicatos que lutam em defesa do setor, em geral os produtores rurais do município em sua grande maioria participam de algum segmento organizador do setor.

A pesquisa de campo foi realizada com produtores rurais que são associados à Associação dos Produtores de Matérias-Primas para as Indústrias de Bioenergia de Goiás (APMP), que cultivaram cana-de-açúcar e as demais culturas (soja, milho, sorgo) na safra 2009/2010 e que suas propriedades rurais estejam no município de Rio Verde-GO.

Dentre os 44 produtores rurais associados da APMP, enquadraram-se nas delimitações desta pesquisa apenas cinco produtores, cujas suas propriedades estão no município de Rio Verde-GO, que cultivaram cana-de-açúcar e as demais culturas no ano agrícola pesquisado; sendo que dois são sócios. Apesar de serem os dois associados da APMP os seus dados são iguais sendo assim, foram considerados uma única propriedade perfazendo um total de quadro propriedades analisadas.

O ano agrícola 2009/2010 foi escolhido devido ao preço final da cana-de-açúcar a ser pago ao produtor, ser determinado apenas em 15/04/2011 pela CONSECANA (Conselho dos Produtores de Cana-de-açúcar, Açúcar e Álcool do Estado de São Paulo), e por já ter sido totalmente comercializada a safra de grãos. 


\subsection{Levantamento de dados}

Os dados coletados foram tabulados em planilha de Excel, utilizando, como metodologia para se determinar o custo de produção, a metodologia do CONAB, citada anteriormente neste trabalho, seus custos de produção foram considerados por hectare, já que os pesquisados têm propriedades de tamanhos diferentes.

O levantamento histórico de custos de produção e preços de comercialização que serviram de base para comparação num período de cinco anos já que a cana-de-açúcar tem este ciclo produtivo foram levantados juntos à CONAB no caso dos custos de produção dos grãos, ORPLANA, no caso dos custos de produção da cana, FAEG no caso dos preços de grãos, e CONSECANA no caso do preço da cana-de-açúcar.

Os custos de produção da soja, do milho safra de verão e do milho safrinha foram levantados junto à CONAB que na sua série histórica traz custos do município de Rio VerdeGO o que não necessitou de nenhum ajuste nos dados, o sorgo não tem divulgada essa informação o que impossibilitou utilizá-lo para comparação.

A cana-de-açúcar como é uma cultura relativamente nova na região não há dados para Goiás, foram levantados seus custos junto a ORPLANA, cujos custos foram mantidos na metodologia original e para o Estado de São Paulo, sendo observados e de acordo com informações da própria associação não se diferem dos custos que seriam obtidos em Goiás, já que é um Estado tradicional na agricultura com utilização de tecnologia de ponta.

Os preços dos grãos foram obtidos junto a FAEG e mediante o cálculo de média simples levando em consideração de julho de um ano até junho do ano seguinte, período adequado em que geralmente acontece o ciclo completo desde o plantio até a comercialização dos grãos. Já o preço final da cana-de-açúcar é obtido em 15 de abril do ano seguinte ao seu corte, sendo assim, o produtor recebe $80 \%$ do produto entregue de acordo com cotações mensais de (ATR) (Açúcar Total Recuperável) informados pela CONSECANA e os $20 \%$ restante somente em 15 de abril do ano seguinte quando a CONSECANA informar o preço final do ATR para aquela safra, foi utilizado então, o preço final do ATR praticado a cada ano na série histórica. Como demonstra o Quadro 1, com os preços dos produtos considerados para análise da série histórica dos dados.

A renda bruta foi obtida a partir da produção em sacas ou toneladas por hectare multiplicada pelo preço médio de cada produto, o resíduo econômico foi obtido com a subtração do custo total de cada produto da renda bruta do respectivo produto.

Quadro 1 - Preços dos Produtos Município de Rio Verde - GO safras 2005/2006 a 2009/2010.

\begin{tabular}{|l|c|c|c|c|c|}
\hline PRODUTOS & $2005 / 2006$ & $2006 / 2007$ & $2007 / 2008$ & $2008 / 2009$ & $2009 / 2010$ \\
\hline SOJA (R\$/saca) & 22,85 & 25,02 & 37,81 & 39,78 & 34,60 \\
\hline MILHO (R\$/saca) & 10,20 & 15,27 & 20,57 & 17,19 & 14,12 \\
\hline SORGO (R\$/saca) & 8,16 & 11,43 & 16,28 & 13,60 & 10,95 \\
\hline CANA (R\$/tonelada)* & 43,02 & 46,65 & 35,51 & 47,14 & 54,30 \\
\hline
\end{tabular}

*Para o preço da cana foi considerado $145 \mathrm{~kg}$ de ART por tonelada nos 3 primeiros anos e $135 \mathrm{~kg}$ nos 2 últimos Fonte: Dados adaptados a partir de FAEG (2011) e CONSECANA (2011). 
O levantamento dos custos e do preço obtido com a venda da produção junto às quatro propriedades pesquisadas foi feito através de entrevista com os produtores rurais, levando em consideração todas as especificidades de cada uma delas como segue:

Propriedade 1 - a única composta por dois sócios, tem uma área total de 2.375,42 hectares de áreas próprias e arrendamentos, destes na safra 2009/2010 foram cultivados na safra de verão 1.713,51 hectares de soja, 112,7 de cana-de-açúcar e 549,21 são destinados a pastagens para criação de gado de corte e aluguel. Na safrinha foram cultivados 985,10 hectares de milho o que lhes concedeu no ano em estudo uma área de 3.360,52 hectares explorados. Seus proprietários além de se dedicarem à agricultura são consultores, participam ativamente de órgãos representativos de classe, sempre ligados à agricultura.

Propriedade 2 - Com área total de 1.300 hectares, distribuídos por talhões onde na safra 2009/2010 foram plantados 1.078 hectares de soja, 100 hectares de milho safra verão, 106 hectares de cana-de-açúcar, os 13 hectares restantes são três hectares destinados a uma granja de produção de suínos no sistema de integração e 10 hectares destinados ao último lote de gado de corte criado no sistema de semiconfinamento, atividade que o mesmo continuará apenas na ultima etapa do processo, apenas comprando animais magros, engordando no confinamento e vendendo. Na safrinha ou segunda safra foram cultivados 279 hectares de milho e 250 hectares de sorgo, assim a propriedade safra estudada plantou nas duas safras um total de 1.813 hectares. O produtor exerce outras atividades junto a cooperativas, e associações não dedicando o seu tempo exclusivamente à atividade agrícola. No entanto, tais atividades são relacionadas ao setor agrícola.

Propriedade 3 - com área total de 836 hectares, na safra em estudo cultivou 750 hectares com soja na safra de verão e 86 com cana-de-açúcar, na safrinha plantou 360 hectares de milho, com uma área total em cultivo de 1.196 hectares. Sua propriedade não teve no ano estudado outra atividade além da agricultura, no entanto, já diversificou e entrou na pecuária de corte, com nova área recém-adquirida, dedica seu tempo integral à atividade.

Propriedade 4 - com área total de 667,40 hectares, cultivou na safra 2009/2010 532,40 hectares de soja. 135 hectares de cana-de-açúcar e na safrinha 387 hectares de milho, tendo cultivado um total de $1.054,40$ hectares naquele ano, seu proprietário se dedica exclusivamente a agricultura.

\section{Resultados e discussão}

Para chegar aos dados a serem analisados da série histórica de cinco anos da soja foram coletados junto à $\mathrm{CONAB}$ dados de produtividade e custos, os preços médios da soja foram coletados junto à FAEG e feito a média dos meses de junho de um ano a julho no ano seguinte, assim então somam-se os preços médios mensais de junho de 2005 a julho de 2006 e dividindo pelo número de meses do período 12 , encontrou-se o preço médio de venda da soja daquele ano de $\mathrm{R} \$ 22,85$. Nos demais anos os cálculos foram feitos da mesma forma.

Observando os fatores que compuseram o custo de produção da soja na safra 2009/2010 foi verificado que alguns itens apresentam grandes diferenças entre a CONAB e os quatro pesquisados, no item I despesas de custeio da lavoura, o pesquisado 1 apresenta um custo $41,11 \%$ acima do custo da CONAB enquanto os demais, o pesquisado 2 apenas $4 \% \mathrm{e}$ os pesquisados 3 e 4 ficaram com valores menores. No item II despesas pós-colheita foi constatado que todos ficaram abaixo do custo da CONAB e no III despesas financeiras, foi identificado que o pesquisado 1 não informou que aplica capital de terceiros enquanto os 
demais utilizam, o pesquisado 2 esse valor foi maior do que o apresentado pela CONAB enquanto dos pesquisados 3 e 4 foram menores.

Por fim nos itens IV, V e VI permanecem as diferenças entre o custo CONAB e os produtores analisados, chegando assim a um custo final de produção de soja onde o pesquisado 1 apresenta um custo $11,84 \%$ acima do custo CONAB o pesquisado 2 praticamente igual, o pesquisado $310,46 \%$ abaixo do custo CONAB e o pesquisado $414,79 \%$ também abaixo do custo CONAB. Assim, o custo apurado pela CONAB deve se tornar objetivo para o pesquisado 1 e os demais devem continuar reduzindo seus custos desde que mantenham os índices de produtividade.

Os custos de produção da cana de açúcar para uma produção de cinco anos com produtividade média de 85 toneladas por corte e com ATR médio de $135 \mathrm{~kg}$ por tonelada. Não há dados da CONAB para comparação como as demais culturas, portanto, foram utilizados dados comparativos da ORPLANA, o que dificulta a comparação já que ela não apresenta seus dados em detalhes como as planilhas de custo de produção da CONAB, contudo, foi empregada a mesma estrutura dos custos dos grãos da CONAB com as informações de custos dos pesquisados sobre a cana.

Os custos de produção da cana de açúcar apresentados no Quadro 25 foram coletados junto aos produtores, sendo que estes apresentaram o custo de implantação e passaram as informações de que produtos e operações já foram feitos na soca da cana que permanece no solo para mais quatro rebrotas e cortes, assim, todos os custos foram distribuídos ao longo de cinco anos. $\mathrm{O}$ custo total da cultura ficou apenas do pesquisado 1 muito acima dos demais, porém, esta abaixo do custo demonstrado pela ORPLANA. Foi observado ainda que neste custo de produção da ORPLANA três itens tem um peso muito grande dentro dos custos que são remuneração da terra, depreciação e remuneração do capital, eles representam $42,94 \%$ do custo total, enquanto com os dados dos produtores esse percentual não chega a $10 \%$ do custo total.

Os demais pesquisados tiveram um custo total bem semelhantes, ressaltando que o pesquisado 3 utilizou quase na sua totalidade na implantação da lavoura recursos próprios, a parte de recurso de terceiros que usou a empresa parceira não cobrou juros justificando assim os juros não participarem da composição dos seus custos de produção.

Apresentados os custos de produção e suas análises por cultura seguiu-se para analisar a rentabilidade auferida pelos produtores na safra 2009/2010 estudada.

No quadro 2 foram apresentados os dados do pesquisado 1, sabendo que ele cultivou uma área total de 1.713,51 hectares de soja que, sua produtividade ficou abaixo do esperado que pela CONAB era de 54,16 sacas/ha enquanto ele só conseguiu 49,48 sacas/ha, seu custo também ficou acima do esperado portanto ele teve nesta safra um prejuízo de $\mathrm{R} \$ 19,54 / \mathrm{ha}$ perfazendo um prejuízo total $\mathrm{R} \$ 33.473,76$ com a soja. Plantou 985,1 hectares de milho safrinha o que representa $53,94 \%$ de sua área total cultivada, sua produtividade foi bem acima da esperada pela CONAB que era de 70 sacas/ha e ele conseguiu 100,24 sacas/ha, seu preço de venda também ficou acima da média do ano que era $\mathrm{R} \$ 14,12$ por saca enquanto ele vendeu a $\mathrm{R} \$ 17,49$ o que gerou um resíduo econômico com o milho de $\mathrm{R} \$ 267.750,18$, e por fim cultivou 112,7 hectares de cana-de-açúcar, que mesmo com seu alto custo de produção, animou o produtor, que no primeiro ano conseguiu $\mathrm{R} \$ 8.042,08$ de receita bruta sem diluir ao longo dos cinco anos, isso devido ele ter aumentado sua área plantada e ter sido o fornecedor de mudas para a nova área, contudo, considerando os dados para cinco anos, a receita média para esse período gera um resíduo econômico de $\mathrm{R} \$ 286,39$ por hectare. Com os dados 
apresentados os grãos cultivados apresentam um resultado final de $\mathrm{R} \$ 136,72$ por hectare e a cana $\mathrm{R} \$ 286,38$.

Quadro 2 - Produtividade, preço de venda, custo de produção e resíduo econômico do pesquisado 1 por hectare e por produto em Rio Verde-GO, safra 2009/2010.

\begin{tabular}{|l|r|r|c|}
\hline Pesquisado 1 & \multicolumn{1}{c|}{ Soja } & \multicolumn{1}{c|}{$\begin{array}{c}\text { Milho } \\
\text { safrinha }\end{array}$} & $\begin{array}{c}\text { Cana-de- } \\
\text { açúcar }\end{array}$ \\
\hline $\begin{array}{l}\text { PRODUTIVIDADE (saca ou } \\
\text { tonelada/hectare) }\end{array}$ & 49,48 & 100,24 & 85 \\
\hline Quilos de ATR (kg de ATR/Tonelada) & - & - & 135 \\
\hline PREÇO (R\$/saca/tonelada) & 34,26 & 17,49 & 0,4022 \\
\hline RENDA BRUTA (R\$/ha) & $1.695,18$ & $1.753,20$ & $4.615,25$ \\
\hline CUSTO TOTAL (R\$/ha) & $(1.714,72$ & $1.481,40$ & $4.328,87$ \\
\hline RESÍDUO ECONÔMICO (R\$/ha) & 271,80 & 286,38 \\
\hline
\end{tabular}

Fonte: Dados da pesquisa

Foi o produtor rural mais diversificado estudado, e o único que cultivou milho na safra de verão e sorgo na safrinha, justificando que possui outra atividade na fazenda que consome estes produtos e ele não fica só na mão do mercado para esses produtos.

Tem seus resultados apresentados no Quadro 3, cultivou neste ano agrícola 1.078 hectares de soja com uma produtividade média de 52,52 sacos/ha que gerou um resíduo econômico total de $\mathrm{R} \$ 285,93$ por hectare, cultivou ainda 100 hectares de milho com uma produtividade $143,41 \mathrm{sc} /$ ha contra $100 \mathrm{sc} /$ ha esperadas pela CONAB, que mesmo com esse ótimo índice de produtividade gerou um resíduo econômico negativo de $\mathrm{R} \$ 82,57$ por hectare, na safrinha cultivou 529 hectares que representam $45 \%$ do total de sua área na safra de verão, sendo que com o milho obteve uma produtividade de 110 sacas/ha e com o sorgo 53,58 sacas/ha, índices que para a CONAB seriam de 70 sacas/ha de milho safrinha e 50 sacas/ha de sorgo, portanto bons índices de produtividade que devido ao custo e ao preço de venda negociado geraram para o milho $R \$ 796,41$ de resultado positivo por hectare e $R \$ 0,64$ de resultado negativo para o sorgo. A cana de açúcar ocupou uma área de 106 hectares e gerou um resíduo econômico de $\mathrm{R} \$ 1.049,65$ por hectare. O resultado final dos grãos na safra $2009 / 2010$ foi de $R \$ 316,24$ por hectare nas duas safras contra $R \$ 1.049,65$ por hectare apresentados pela cana.

O Quadro 4 demonstra os dados do pesquisado 3, na safra 2009/2010 cultivou 750 hectares de soja, o único entre os pesquisados que conseguiu o índice de produtividade acima do considerado pela CONAB, colheu 55 sacas de soja por hectare, e seu preço de venda também ficou acima da média tendo conseguido $\mathrm{R} \$ 35,00$ por saca, mostrando-se eficiente já que conseguiu aliar preço, produtividade e baixo custo de produção, já que este também ficou abaixo do esperado pela CONAB. Na safrinha cultivou 360 hectares de milho, que representou $43 \%$ de sua área total, a plantação sofreu com efeitos climáticos o prejudicando na produtividade, colheu apenas 80 sacas de milho por hectare, teve ainda problemas na época da colheita, foi informado que faltariam armazéns para receber o grão fechou contratos antecipados com medo de não ter onde entregar sua produção ao preço de $\mathrm{R} \$ 12,00$ por saca, 
preço que posteriormente reagiu, porém ele já tinha fechado seu contrato teve que entregar o grão e ficou com um resíduo econômico negativo de $\mathrm{R} \$ 304,42$ por hectare.

Quadro 3 - Produtividade, preço de venda, custo de produção e resíduo econômico do pesquisado 2 por hectare e por produto em Rio Verde-GO, safra 2009/2010.

\begin{tabular}{|c|c|c|c|c|c|}
\hline Pesquisado 2 & Soja & $\begin{array}{l}\text { Milho } \\
\text { verão }\end{array}$ & $\begin{array}{l}\text { Milho } \\
\text { safrinha }\end{array}$ & $\begin{array}{l}\text { Sorgo } \\
\text { safrinha }\end{array}$ & $\begin{array}{l}\text { Cana-de- } \\
\text { açúcar }\end{array}$ \\
\hline $\begin{array}{l}\text { PRODUTIVIDADE } \\
\text { tonelada/hectare) }\end{array}$ & 52,52 & 143,41 & 110,00 & 53,58 & 85,00 \\
\hline 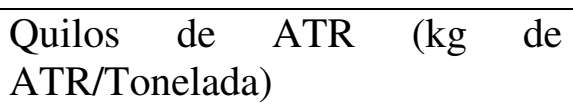 & - & - & - & - & 135 \\
\hline PREÇO (R\$/saca/Kg ATR) & 34,06 & 13,00 & 16,04 & 10,76 & 0,4022 \\
\hline RENDA BRUTA (R\$/ha) & $\begin{array}{c}1.788,8 \\
3\end{array}$ & $1.864,33$ & $1.764,40$ & 576,52 & $4.615,25$ \\
\hline CUSTO TOTAL (R\$/ha) & $\begin{array}{c}1.502,9 \\
0\end{array}$ & $1.946,90$ & $1.017,49$ & 577,16 & $3.565,59$ \\
\hline $\begin{array}{l}\text { RESÍDUO } \\
\text { (R\$/ha) }\end{array}$ & 285,93 & $(82,57)$ & 746,91 & $(0,64)$ & $1.049,65$ \\
\hline
\end{tabular}

Fonte: Dados da pesquisa.

Plantou em 2009/2010 86 hectares de cana, teve o menor custo de produção dentre os pesquisados o que gerou um resíduo econômico de $\mathrm{R} \$ 1.306,26$ por hectare. Os grãos devido ao baixo desempenho do milho safrinha fecharam na safra 2009/2010 com um resultado de $\mathrm{R} \$ 274,35$ por hectare contra um resultado de $\mathrm{R} \$ 1.306,26$ por hectare de cana, o melhor resultado dentre os pesquisados.

Quadro 4 - Produtividade, preço de venda, custo de produção e resíduo econômico do pesquisado 3 por hectare e por produto em Rio Verde-GO, safra 2009/2010.

\begin{tabular}{|c|c|c|c|}
\hline Pesquisado 3 & Soja & $\begin{array}{l}\text { Milho } \\
\text { safrinha }\end{array}$ & $\begin{array}{l}\text { Cana-de- } \\
\text { açúcar }\end{array}$ \\
\hline $\begin{array}{lll}\text { PRODUTIVIDADE } & \text { (saca } & \text { ou } \\
\text { tonelada/hectare }) & \end{array}$ & 55,00 & 80,00 & 85 \\
\hline Quilos de ATR (kg de ATR/Tonelada) & - & - & 135 \\
\hline PREÇO (R\$/saca/Kg ATR) & 35,00 & 12,00 & 0,4022 \\
\hline RENDA BRUTA (R\$/ha) & $1.925,00$ & 960,00 & $4.615,25$ \\
\hline CUSTO TOTAL (R\$/ha) & $1.372,84$ & $1.264,42$ & $3.308,98$ \\
\hline RESÍDUO ECONÔMICO (R\$/ha) & 552,16 & $(304,42)$ & $1.306,26$ \\
\hline
\end{tabular}

Fonte: Dados da pesquisa. 
O Quadro 5 apresenta o resumo dos dados do pesquisado 4, que na safra 2009/2010 cultivou 532,4 hectares de soja e conseguiu dentre os pesquisados o melhor resultado de produtividade que foi de 56 sacas de soja por hectare, o preço médio ficou abaixo da média do ano que foi de $\mathrm{R} \$ 32,12$ por saca e seu custo foi o menor por hectare dentre os pesquisados $\mathrm{o}$ que gerou um resíduo econômico de $\mathrm{R} \$ 618,53$ por hectare.

Quadro 5 - Produtividade, preço de venda, custo de produção e resíduo econômico do pesquisado 4 por hectare e por produto em Rio Verde-GO, safra 2009/2010.

\begin{tabular}{|l|c|c|c|}
\hline Pesquisado 4 & \multicolumn{1}{l|}{ Soja } & Milho safrinha & Cana \\
\hline PRODUTIVIDADE (saca ou tonelada/hectare) & 56,00 & 110,00 & 85 \\
\hline Quilos de ATR (kg de ATR/Tonelada) & - & - & 135 \\
\hline PREÇO (R\$/saca ou R\$/kg ATR) & 32,12 & 12,50 & 0,40 \\
\hline RENDA BRUTA (R\$/ha) & $1.798,72$ & $1.375,00$ & $4.615,25$ \\
\hline CUSTO TOTAL (R\$/ha) & $1.306,47$ & $1.109,13$ & $3.410,11$ \\
\hline RESÍDUO ECONOMICO (R\$/ha) & 618,53 & 265,87 & $1.205,14$ \\
\hline
\end{tabular}

Fonte: Dados da pesquisa.

Plantou 387 hectares de milho safrinha que representa 58\% da sua área total com uma produtividade média de 110 sacas por hectare, com o preço de venda de $\mathrm{R} \$ 12,50$ por saca, que gerou um resíduo econômico de $\mathrm{R} \$ 265,87$ por hectare, e por fim, plantou 135 hectares de cana, motivado por esta cultura que sofre menos com os efeitos climáticos, que gerou um resíduo econômico de $\mathrm{R} \$ 1.205,14$ por hectare.

\section{Considerações finais}

Levantaram-se os custos de produção da safra 2009/2010 dos quatro pesquisados com cada cultura separadamente, soja, milho, sorgo e cana-de-açúcar utilizando a metodologia da CONAB, chegou-se ao resíduo econômico de cada cultura.

Coletaram os dados históricos de custo de produção junto à CONAB das safras 2005/2006 a 2009/2010 da soja, milho verão, milho safrinha e sorgo, dos mesmos produtos calcularam-se os preços médios de comercialização com dados fornecidos pela FAEG. Os dados históricos de custos da cana-de-açúcar foram levantados junto à ORPLANA, os preços finais pagos aos produtores foram coletados junto à CONSECANA.

Com as planilhas elaboradas foi possível chegar ao custo de produção para cada produto e pesquisado separadamente, dois dos quatro pesquisados não tinham esta informação e se surpreenderam com o resultado. Ficou claro que o custo de alguns fatores que compõem o custo de produção são responsáveis pelo custo elevado de produção, assim se visualizam fatores que são passíveis de redução. Ficou evidenciada a importância das informações sobre custos de produção para uma possível negociação antecipada dos produtos, e tomada de decisão no ambiente da empresa rural.

Concluiu-se analisando a série histórica que são vários fatores que influenciam tanto os custos de produção quanto o preços das commodities não tendo nenhuma relação direta de aumento ou diminuição dos seus valores, dificultando uma possível previsão antecipada de 
como se comportará o mercado para a próxima safra. No período analisado de cinco safras o resultado econômico dos grãos foi negativo em dois anos e da cana em apenas um, garantido uma rentabilidade melhor para a cana-de-açúcar.

Analisando os resultados dos quatro pesquisados na safra 2009/2010 a cana foi mais rentável em $100 \%$ do que os grãos (soja, milho, milho safrinha e sorgo) na proporção cultivada de cada cultura.

Assim conclui-se que o melhor é diversificar as culturas mesmo a cana tendo apresentado a melhor rentabilidade na safra estudada, para não ficar preso a um único produto (grãos ou cana) com sua volatilidade de preço de venda e custo de produção. Observando que a cana só é cultivada com contrato de fornecimento ficando preso a um único comprador enquanto os grãos não apresentam esse problema, analisando quanto a riscos climáticos, os grãos estão em desvantagem porque a cana apresenta maior resistência as suas oscilações.

O trabalho limitou-se a estudar quatro empresas rurais que se adequavam às delimitações deste trabalho, os pesquisados foram consultados antecipadamente quanto à disponibilidade de fornecimento de seus dados reais, porém, na coleta de dados ficaram muito receosos o que atrasou a conclusão do trabalho. A adequação dos dados de um pesquisado que possuía um controle próprio de dados foi trabalhosa já que o mesmo passou os dados compilados e não dispunha de tempo para abrir seus dados e passar na forma que era necessário para adequação a metodologia da $\mathrm{CONAB}$, dois outros não dispunham de qualquer controle de custos o que atrasou a conclusão de seus dados já que seus custos foram extraídos direto das notas fiscais, recibos e tendo que calcular sua hora máquina de cada uma da propriedade.

Espera-se que este trabalho sirva de instrumento para construção e/ou reformulação de políticas públicas voltadas para o setor, além de servir como fonte de pesquisa e informação para os produtores rurais da região tão carentes das mesmas, além se sugerir novos estudos a fim de que se construa um banco de dados com dados de Goiás.

\section{Referências}

APMP. Associação Paulista do Ministério Público. Estatuto Social da Associação dos Produtores de Matérias-Primas para as Indústrias de Bioenergia de Goiás. São Paulo: APMP, 2009.

CONAB. Companhia Nacional de Abastecimento. Acompanhamento da safra Brasileira: cana-de-açúcar safra 2009. Brasília: CONAB, 2010. Disponível em:

<http://www.conab.gov.br/conabweb/download/safra/3cana_09.pdf>. Acesso em: 05/02/2010.

CONAB. Companhia Nacional de Abastecimento. Custo de produção - Culturas de Verão

- Série Histórica. Brasília: CONAB, 2011. Disponível em:

$<$ http://www.conab.gov.br/conteudos.php?a=1277\&t=\&Pagina_objcmsconteudos=1\#A_objc msconteudos>. Acesso em: 15/05/2011.

CONSECANA. Conselho dos Produtores de Cana de açúcar, Açúcar e Álcool do Estado de São Paulo. Dados e cotações. Disponível em: http://www.unica.com.br/q10/. Acesso em: $15 / 08 / 2011$

CREPALDI, S. A. Contabilidade gerencial: teoria e prática. São Paulo: Atlas, 1998.

CREPALDI, S. A. Contabilidade rural: uma abordagem decisorial. 3.ed. São Paulo: Atlas, 2005. 
CREPALDI, S. A. Curso básico de contabilidade de custos. São Paulo: Atlas, 1999.

FAEG. Federação da Agricultura e Pecuária de Goiás. Preços de produtos agrícolas. Disponível em: <http://www.sistemafaeg.com.br/faeg/site/Cotacao.do>. Acesso em: $12 / 07 / 2011$

IBGE. Instituto Brasileiro de Geografia e Estatística. Censo Agropecuário 2006. Disponível em: <http://ibge.gov.br/home/estatistica/economia/agropecuaria/censoagro $>$. Acesso em: $15 / 06 / 2010$.

INCRA. Evolução da Estrutura Fundiária Brasileira. Disponível em: <http://www.incra.gov.br>. Acesso em: 20/04/2010.

JORGE, Fauzí Timaco; MOREIRA, José Otávio de Campos. Economia, notas introdutórias. São Paulo: Atlas, 1995.

KALECKI, Michal. Teoria da dinâmica econômica. São Paulo: Abril Cultural, 1983.

LACKI, Polan. Os pobres rurais também podem ser eficientes... e quando o forem deixarão de ser pobres. Disponível em: <http://www.polanlacki.com.br/br/artigosbr/os_pobres.htm>. Acesso em: 12/09/2011.

LEONE, George S. G. Custos: planejamento, implantação e controle. 2.ed. São Paulo: Atlas, 1996.

MARTINS, Eliseu. Contabilidade de custos. 9.ed. São Paulo: Atlas, 2003.

MATSUNAGA, M. et al. Metodologia de custo de produção utilizado pelo IEA. Agricultura em São Paulo, São Paulo, v.23, n.1, p.123-139. 1976.

MEDEIROS, Luiz Edgar. Contabilidade de custos: um enfoque prático. Porto Alegre: Ortiz, 1994.

NORONHA, José Ferreira et al. Análise da rentabilidade da atividade leiteira no estado de Goiás. Goiânia: UFG, 2001.

NORONHA, José Ferreira. Projetos agropecuários: administração financeira, orçamentação e avaliação econômica. Piracicaba: Editora ESALQ, 1981.

ORPLANA, Organização de Plantadores de Cana da Região Centro Sul. Custos de produção. Disponível em: <http://www.orplana.com.br/novosite/custos_de_producao>. Acesso em: 10/08/2011.

RIO VERDE. Lei Municipal 5.200/2006. Disponível em: $<$ http://www.rioverdegoias.com.br/arquivos/LEI_5200_2006.pdf>. Acesso em: 24/04/2010.

ROSSETTI, José Paschoal. Introdução à economia. São Paulo: Atlas, 1997.

SANTOS, Gilberto José dos; MARION, José Carlos; SEGATTI, Sonia. Administração de custos na agropecuária. 3. ed. São Paulo: Atlas, 2002.

SENAR. Serviço Nacional de Aprendizagem Rural. Administração Rural. Goiânia: SENAR, 1998.

SEPLAN. Secretaria de planejamento e desenvolvimento de Goiás. Estatística. Disponível em: <http://www.seplan.go.gov.br/sepin/>. Acesso em 08/02/2010. 